ACTA UNIVERSITATIS LODZIENSIS

FOLIA LITTERARIA POLONICA 1(39) 2017

http://dx.doi.org/10.18778/1505-9057.39.12

Magdalena Szydłowska*

\title{
Radio Rajdowe Rozgłośni Regionalnej Polskiego Radia w Olsztynie 1998-2016
}

$\mathrm{Na}$ antenie publicznego nadawcy formuła omawianego profilu radia funkcjonuje już od dziewiętnastu lat. Mam na myśli Rozgłośnię Polskiego Radia w Olsztynie ${ }^{1}$. Radio Rajdowe jest specyficzną monograficzną konstrukcją wpisaną w określoną problematykę i sytuację. Jest jedyną tego typu inicjatywą publicznego radia w Europie, zatem interesującym i godnym uwagi kontekstem funkcjonowania radia. Radio Rajdowe to figura wywołana obecnością nadawcy w przestrzeni publicznej. Nadawcy, który jest jej kronikarzem i uczestnikiem. W tym wypadku konsekwentnym i sprawnym odbiorcą danych i ich przekaźnikiem. Wojciech Jermakow, dziennikarz Radia Olsztyn, pilot rajdowy, współtwórca i prezenter jednoznacznie wskazuje, że: „Radio Rajdowe jest to kwintesencja radiofonii [...] tyle, ile przy obecnych możliwościach technicznych i technologicznych można wycisnąć z radia, to my tyle wycisnęliśmy"2. Radio Rajdowe wpisuje się w przestrzeń aktywności audialnego medium, w nowym środowisku technologicznym, w sytuacji konwergencji pozwalającej na eksploracje multimedialne.

W tym miejscu należy się zastanowić, czym jest współczesne radio i czy można tego rodzaju pytanie zadać, stosując, oczywiście w odniesieniu do wskazanej sytuacji medialnej, stosowny kontekst czasowy. Bardziej zasadne wydaje się sformułowanie pytania nieco inaczej, czym jest radio i czym winno w prymarnym kontekście być? Zatem można by pokusić się o podstawową definicję: radio jest nadawcą, sprecyzowanym podmiotem $\mathrm{w}$ relacji z odbiorcą. Jest ak-

* Dr, e-mail: magdalena_szydlowska@ro.com.pl; Uniwersytet Warmińsko-Mazurski w Olsztynie, Instytut Dziennikarstwa i Komunikacji Społecznej; 10-725 Olsztyn, ul. Kurta Obitza 1.

${ }^{1}$ Radio Olsztyn jest nadawcą publicznym działającym na terenie północno-wschodniej Polski. Najstarsza rozgłośnia radiowa regionu. Istnieje od 1952 r. Podmiot wpisany w przestrzeń kulturową Warmii i Mazur. Można zaryzykować, iż jest to jedna z najistotniejszych instytucji regionu. M. Kropacz-Szydłowska, Od Ekspozytury Polskiego Radia do Radia Olsztyn S.A. Z dziejów olsztyńskiej radiofonii w latach 1992-1993, Polskie Towarzystwo Historyczne. Oddział: Instytut Dziennikarstwa i Komunikacji Społecznej UWM, Olsztyn 2012, s. 7 i nast.

${ }^{2}$ Rozmowa z Wojciechem Jermakowem, dziennikarzem Radia Rajdowego, przeprowadzona 15.05.2016 r.; zarejestrowana rozmowa w posiadaniu autorki tekstu. 
tywnym medium kontaktu, kanałem łączącym twórców i odbiorców. Tak zapewne jest w tym wypadku. Jednocześnie wskazać należy, iż różnorodność oferty programowej nadawcy wychodzi, a przynajmniej wychodzić winna naprzeciw oczekiwaniom społecznym, winna być barometrem zmian. I jest to praktyka już zagospodarowana i osadzona w realiach. Radio wszak podlega ewolucji, podąża za potrzebami, oczekiwaniami. Dotyczy to zarówno podejmowanej problematyki, ale także gatunków dziennikarskich, czyli formuły przekazu. Prymarna powinność informowania, odnotowywania jest jednak punktem zasadniczym i podstawowym kontekstem audialnym. To jest perspektywa nadawcy, który konfrontuje się z odbiorcą, stale zmiennym i zachłannym. Ewolucja społeczeństwa, także w kontekście komunikacyjnym, jest dynamiczna i wymusza na nadawcy stosowną aktywność. Nie ulega wątpliwości, że media są odzwierciedleniem tej sytuacji i konsekwentnie stają się zwierciadłem przemian i ich uczestnikiem, także w sensie partycypacyjnym. Rozumiem to zdanie w sensie dosłownym. Owe wskazania dotyczą także konstruktu, o którym mowa - radia rajdowego.

\section{Radio rajdowe - próba definicji}

Czym zatem jest radio rajdowe i jak należy je postrzegać? Początkowo przyszła mi na myśl koncepcja formatowania radia. Rzecz rozpoznana i formalnie usankcjonowana, zgodnie ze wskazaniem radioznawcy Stanisława Jędrzejewskiego, iż u podłoża radia formatowanego tkwi przeświadczenie, że słuchacz decyduje się na wybór określonej oferty nie dla pojedynczej audycji, lecz dla całego programu3 . Wobec tego program jednorodny i spójny tematycznie wydaje się atrakcyjny. Jednocześnie ta formuła jak najbardziej przynależy koncepcji radia rajdowego. Tym bardziej, iż formatowanie związane jest $\mathrm{z}$ ofertą programową, w tym wypadku szeroko pojętą problematyką rajdową, która wygeneruje jak największą liczbę słuchaczy, czyli grupę docelową - zdefiniowanych adresatów. Tak sprecyzowana oferta jednoznacznie wpływa na zainteresowanie audytorium.

Format radia to kolaż muzyki i problematyki na antenie. Odpowiednio sformatowane radio będzie budowało wysokie wskaźniki zasięgu w swojej grupie docelowej, pozostając tym samym w opozycji do mediów o uniwersalnej ramówce, które dziś wymuszają selektywne pozycjonowanie u słuchacza. Oczywiście tego typu rozgłośnie mogą posiadać imponujące audytorium, jednak nie jest ono tak jednorodne, jak w przypadku radia monograficznego.

${ }^{3}$ Zob. S. Jędrzejewski, Radio w komunikacji społecznej. Rola i tendencje rozwojowe, Wydawca Profi-Press Sp. z o.o., Warszawa 2003, s. 147. 
Jednocześnie przychodzi mi na myśli nieco inna koncepcja zdefiniowania radia rajdowego, związana $\mathrm{z}$ ideą dziennikarstwa specjalistycznego, przykładowo: muzycznego, informacyjnego, ekonomicznego, sportowego, dziennikarstwa sprofilowanego, kompetencyjnie osadzonego. Radio rajdowe to przejaw aktywnego dziennikarstwa sportowego, uściślając - motoryzacyjnego. Dziennikarz staje się specjalistą w określonej problematyce, ze względu na stałe i systematyczne jej penetrowanie, często bazuje na opinii ekspertów, zdarza się także, iż sam dołącza do wybranego profesjonalnego grona, np. rajdowców.

Problematyka rajdowa jest stale, w różnorodnej formule, obecna na antenach radiowych, najczęściej w postaci stricte informacyjnej, stanowiąc element serwisów bądź będąc oddzielną audycją. Może ona być także penetrowana w sprofilowanych blokach tematycznych poświęconych motoryzacji lub szeroko pojętej tematyce sportowej. Jedyną na polskiej antenie audycją rajdową jest „Odcinek Specjalny”, program Karola Ferenca w Akademickim Radiu Luz ${ }^{4}$. Audycja posiada swój aktywny profil na Facebooku.

Oczywiście na świecie istnieją tego typu radia, choć ich liczba nie jest imponująca i nie są to stacje publiczne. Egzemplifikację stanowi chociażby kanadyjskie internetowe Race Time Radio nadające podczas rajdów w Ameryce Północnej ${ }^{5}$. A także prekursor koncepcji, istniejąca od 1973 roku, rozgłośnia stale obecna na wszystkich najistotniejszych rajdowych wydarzeniach świata - radio internetowe World Rally Radio $\mathrm{WRC}^{6}$, tworzone przez dziennikarzy motoryzacyjnych, których nazwiska są wręcz emblematyczne dla sportu rajdowego: Beck Williams, Colin Clark, Patrick Julies. Obie stacje nadają program w trakcie trwania rajdów, na ich stronach internetowych są także zamieszczone tematyczne podcasty $\mathrm{w}$ formie wywiadów, komentarzy, relacji. Pojawia się tam także przestrzeń przeznaczona na wypowiedzi kibiców. Na stronach obu rozgłośni jest umieszczony plan rajdów, które będą przedmiotem przyszłych relacji. Zatem obie stacje mają charakter mobilny. Wpisuje się to zresztą w koncepcję partycypacji w tego rodzaju sportowych przedsięwzięciach, gdzie komentarz „na żywo” sytuuje odbiorcę w epicentrum eventu. Na tej klasycznej formie stacje kończą swoją działalność. Mamy więc do czynienia z tradycyjną formułą radia, które jest kronikarzem, rejestratorem najważniejszych zdarzeń, w tym wypadku rajdu, wykorzystuje także nowe media, stanowiąc kolaż gatunkowo-stylistyczny.

Wskazane egzemplifikacje są reprezentatywnymi przykładami tego rodzaju funkcjonowania radiowego. Radio rajdowe jest ich lustrzaną perspektywą,

${ }^{4}$ Zob. Odcinek Specjalny, http: //odcinekspecjalny.pl/ [dostęp: 10.05.2016].

${ }^{5}$ Zob. Race Time Radio, RTR, http://tunein.com/radio/William-Hill-Racing-Radio-s149648/ [dostęp: 10.05.2016].

${ }^{6}$ Powstałe w 1973 r. WRC - World Rally Championship można uznać za powód i początek funkcjonowania legendarnego rajdowego radia, World Rally Championship, WRC, http://www. wrc.com/en/wrc/about-wrc/what-is-wrc/page/673-672-.html [dostęp: 10.05.2016]. 
ale dodatkowo, jest także otwartą formułą wielofunkcyjną. Główny prezenter, kronikarz omawianego w niniejszym tekście Radia Rajdowego, Jermakow, na pytanie, czy zna podobne rozgłośnie, odpowiada jednoznacznie:

No właśnie nie, powiem może nieco zuchwale, że nie. To znaczy pomysł na Radio Rajdowe w 1997 roku to był podejrzany pomysł, bo takie radia już były, na wyścigu rajdowym $24 \mathrm{~h}$ LeMans, słynnym 24-godzinnym. Na różnych rundach mistrzostw świata, mistrzostw Europy są takie radia. Jest radio oficjalne WRC z naszymi legendami, które my podpatrujemy i z którymi mieliśmy okazję pracować [...] Zrobiliśmy 99\% radia w radiu, to znaczy graliśmy muzykę, informowaliśmy tak bardzo na bieżąco, że bardziej się nie da. Podtykaliśmy mikrofony wszędzie tam, gdzie się dało podetknąć, do tego komentarz był na bieżąco. Do tego dochodziły jeszcze materiały o historii rajdów, apele do kibiców o bezpieczeństwo. I interakcja, jakiej ja do tej pory nie doświadczyłem nigdzie indziej, mimo tego, że pracowałem w radiu długo. I podejrzewam, że mało kto może się pochwalić taką interakcją. To znaczy, że nam kibice przesyłają SMS-y z pozdrowieniami, z wygłupami, to jest jedno. To, że przez lata udało nam się wypracować jakiś taki styl kibicowania, że na przykład policjanci SMS-ami pozdrawiają kibiców albo załogi karetek czy straży pożarnej, która zabezpiecza te oes-y [odcinki specjalne - M.Sz.]. Ale to, że dzwoni do mnie szef zabezpieczenia rajdu albo dyrektor rajdu i mówi: „Wojtek, podkreślcie raz jeszcze i przypomnijcie kibicom, którzy stoją na oes-ie, o tym i tym, na zakręcie takim i takim. Niech się odsuną od drogi. Jest ich za dużo, jest niebezpiecznie. Delegat do spraw bezpieczeństwa waha się, czy ten oes pójdzie czy nie pójdzie. Przypomnijcie, żeby stanęli od drogi dalej”. My to mówimy. Jest reakcja wśród kibiców. Oczywiści to nie jest tak, że wszyscy kibice słuchają Radia Rajdowego. Tym bardziej, że jak mamy rundę mistrzostw świata, nie wszyscy mówią po polsku. Ale zawsze, co dziesiąty kibic ma to radyjko, słucha. On przekazuje innym: „słuchajcie poważna sprawa. Trzeba się odsunąć”. I to działa. I co jeszcze więcej można w radiu robić. [...] Od 2013 roku „kubicomaniacy” przyszli do rajdów. My się cieszymy z tego powodu, tylko pojawiło się nowe wyzwanie. Jak kibicować? Bo to jest trudny sport do kibicowania. To nie jest dyscyplina stadionowa, halowa. My thumaczymy, że rajd to jest taki organizm, który tworzą wszyscy razem. Kierowca może świetnie pojechać, ale jak kibice będą stali w złym miejscu, to oni ten rajd zepsują. Kibice muszą odpowiednio reagować na to, co się dzieje, żeby ten rajd był udany. Udaje nam się to ${ }^{7}$.

Podobnego zdania jest także jeden z współtwórców Radia Rajdowego, Mariusz Borsiak:

\footnotetext{
${ }^{7}$ Rozmowa z Wojciechem Jermakowem...
} 
[...] za pośrednictwem anteny można zwracać uwagę na bezpieczeństwo związane z tą imprezą, bezpośrednio apelować do słuchaczy o zachowanie zasad. I właściwie jest tak co roku, bo zawsze się znajdą tacy, którzy nie bardzo wiedzą, jak się zachować i stawiają czasami pod znakiem zapytania odcinki specjalne. Ale to już jest taka impreza i trzeba się przyzwyczaić. Ocena naszych działań była zawsze dobra. Za pracę otrzymaliśmy dyplom od Polskiego Związku Motoryzacyjnego.

Jest to bardzo gorąca informacja i rodzaj gorącej publicystyki, Radio Rajdowe ma swoją specyfikę i niuanse. Zawsze nam było bardzo przyjemnie, jak spotykaliśmy się z niezwykle życzliwym przyjęciem u słuchaczy ${ }^{8}$.

Radio Rajdowe jest to klasyczny przejaw funkcjonowania medium kontaktu i swoiste forum wymiany danych. Radio informuje, ale pełni także funkcje organizacyjne. Tym samym urasta do rangi świadomego, konsekwentnego współgospodarza. Jest to więc formuła poszerzona, bazująca na interakcji. Radio wypracowało w ten sposób strategię operowania określonymi narzędziami w kontakcie $\mathrm{z}$ adresatem. Narzędziami, które równolegle z rozwojem technologicznym, z roku na rok, usprawniają działania nadawcy.

Można na ten typ radia spojrzeć z perspektywy antropologicznej, konsekwentnie zresztą z tezą socjologa Paula Connertona, który postrzega to zjawisko w kontekście budowania wspólnoty. Badacz wskazuje, że poznajemy się wzajemnie przez wysłuchiwanie relacji i ich zdawanie, przez wspólnotę trwania. W tym wypadku dziennikarz, jako źródło pośrednie, również poznaje i przekazuje zinterpretowane dane dalej, poniekąd konfrontując się z nimi, reinterpretując je, wciela w życie określony kult ${ }^{9}$. Oczywiście dzieje się to na zasadzie dobrowolności, tak jak w przypadku odbioru radia, ale powtarzalność, a może inaczej konsekwencja nadawcy w realizacji konkretnej problematyki, może wywołać określony skutek, w tym wypadku niesienie przeznaczonej dla słuchaczy treści, jej świadome propagowanie i upowszechnianie, a także budowanie specyficznej więzi w obrębie małej, zdefiniowanej społeczności, jaką bez wątpienia są słuchacze Radia Rajdowego.

Potwierdzeniem istnienia takiej incydentalnej wspólnoty jest stały kontakt ze słuchaczami - uczestnikami rajdu i niezliczona liczba komunikatów tekstowych przesyłanych do dziennikarzy. Przykładowo w 2009 roku, w czasie całego weekendu, kibice nadesłali 4600 wiadomości wszelakiej treści ${ }^{10}$. Oto kilka wybranych egzemplifikacji:

${ }^{8}$ Rozmowa z Mariuszem Borsiakiem, dziennikarzem Radia Rajdowego, przeprowadzona 15.05.2016 r.; zarejestrowana rozmowa w posiadaniu autorki tekstu.

${ }^{9}$ Zob. P. Connerton, Jak społeczeństwa pamiętaja, przekł. i wstęp M. Napiórkowski, Wydawnictwo Uniwersytetu Warszawskiego, Warszawa 1989, s. 202.

${ }^{10}$ W. Jermakow, Łaczymy się z walcem. Jedyne takie Radio Rajdowe, „Co słychać” 2006, nr 5 (23), s. 2-3. 
Powiem tylko tyle, byłem w sobotę na rajdzie i wy tam byliście, potem wróciłem do domu. Chłopaki czułem się tak jakbym stał na oesie. Po prostu nie wiem, jak mam Wam za to dziękować. [...] Halo się pali. Hołek stoi i gasi auto. [...] Radio Rajdowe rewelka!!! Czasy natychmiast, wywiady na żywo - bomba!!! [...] Dzięki Wam, lecąc z odcinka na odcinek, wiedzieliśmy, co jest grane. [...] Popsuliśmy silnik. Załoga 62 501300278. [...] Cieszę się, że rozpropagowaliście „fińskie” zasady kibicowania, które opisałem Wam w mailu. Marzę, aby kiedyś gdzie indziej nawoływano do „polskiego" kibicowania jako synonimu kultury i właściwej postawy. Radio Rajdowe kocham nad życie ${ }^{11}$.

Widać wyraźnie, że treści informacyjne przenikają się z wyrazami aprobaty, ale także aktywnego odnotowania swojej obecności. W tym sensie można zaryzykować tezę, że zespołowa partycypacja wywołuje konstrukcję medium społecznego, działającego formalnie pod egidą regionalnego, publicznego nadawcy, jednak wykraczającego poza kanon publicznego radia. Niemniej, co należy zauważyć, jest to nadal radio w pewnym sensie stale realizujące misję. Zgodnie z definicją radioznawczyni, Urszuli Doliwy, Radio Rajdowe oferuje treści adresowane do grupy społecznej, niewystarczająco eksponowane, pomijane, wręcz niszowe. Radio Rajdowe tworzą dziennikarze, słuchacze, obsługa rajdu i jego uczestnicy. Większość buduje zasób antenowy w formule non profit ${ }^{12}$. I jest to kolejne wskazanie na tego typu kategoryzację. Jeden z twórców Radia Rajdowego, Borsiak wyraźnie definiuje, że:

To takie radio, które wybiło się od matki na niepodległość. Jest to propozycja programowa radia. $Z$ racji tego, że nie wszystkich ten rajd interesował, mieliśmy rozszczepienia anteny. Mogliśmy nadawać na osobnej częstotliwości, bez uszczuplania programu radiowego, który nadal był stałą ofertą dla pozostałych słuchaczy. Jest to radio monograficzne skupione wokół jednej imprezy ${ }^{13}$.

Dziennikarze Radia Rajdowego zasadnie twierdzą, że rokrocznie słuchacze z różnych stron świata dołączają do grona odbiorców radia, śledząc kalendarium wydarzeń i cyklicznie w trakcie ponownego pojawiania się medium w eterze, sygnalizują swoją obecność. Analogicznie, zdaniem Jermakowa, było również w ubiegłym roku:

Radio nadaje na częstotliwości 99,6 i całe Mazury bez problemu obejmujemy, a jeśli chodzi o Internet, to bez ograniczeń. Słuchacze przesyłają nam e-maile z różnych

${ }^{11}$ Tamże.

12 Zob. U. Doliwa, Radio spoleczne: trzeci obok publicznego i komercyjnego sektor radiowy, Wydawnictwo Uniwersytetu Warmińsko-Mazurskiego, Olsztyn 2016, s. 23-24.

${ }^{13}$ Rozmowa z Mariuszem Borsiakiem... 
zakątków świata: Australia, Ameryka Południowa. Zdarzyło się, że pan, który nas słuchał w Europie, jednego dnia słuchał w Berlinie. Następnego dnia gdzieś w Austrii, trzeciego dnia z Francji przesyłał SMS-y. Liczby, trudno jest to mierzyć. Na rajdzie bywa od stu do dwustu tysięcy kibiców. Zakładamy, że co dziesiąty słucha ${ }^{14}$.

Warto także dodać, że Radio Rajdowe nie odnotowuje żadnych wymiernych zysków płynących z tej inicjatywy.

\section{Kilka słów o dziejach Radia Rajdowego}

Historia Radia Rajdowego wpisana jest niejako w charakter regionu i przypisane mu wydarzenia. Borsiak zauważa, że:

Warmia i Mazury to zagłębie sportu rajdowego i odkąd pamiętam, a ja się zawsze zajmowałem sportem, to były dwie takie koronne dyscypliny: piłka siatkowa, no i rajdy. Pamiętam te pierwsze Rajdy Kormoran, w których startował już nieżyjący Marian Bublewicz, potem Krzysztof Hołowczyc. To były jeszcze takie pionierskie czasy i pamiętam już wtedy, że rola radia była dosyć istotna. Dlatego, że wówczas sprawy techniczne, łączenie i tak dalej, były jeszcze w powijakach. Pamiętam, że wówczas proszono wojsko, żeby nadawało relacje z poszczególnych odcinków rajdu. Najczęściej to szwankowało i odcinki unieważniano, dlatego że nie docierały poszczególne dane. I wtedy my w radiu mieliśmy taką szansę, że jak byliśmy na mecie, to mogliśmy te dane przekazać bardzo szybko. A wiadomo, że w tych sportach czas odgrywa najbardziej istotną rolę. Kiedy Rajd Polski pojawił się w okolicach Mikołajek, impreza o niezwykle dużym prestiżu, okazało się, że radio może być bardzo przydatne ${ }^{15}$.

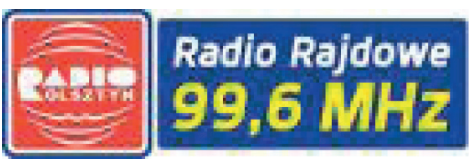

Fot. 1. Logo Radia Rajdowego

Źródło: http://ro.com.pl/72-rajd-polski-zobacz-i-posluchaj/01216452 [dostęp: 10.05.2016].

Decyzja o powstaniu Radia Rajdowego zapadła w 1997 roku. Pośród inicjatorów wymienia się czterech dziennikarzy Radia Olsztyn: Mariusza Bojarowicza, Mariusza Borsiaka, Artura Lewandowskiego i ówczesnego prezesa,

\footnotetext{
${ }^{14}$ Rozmowa z Wojciechem Jermakowem...

${ }^{15}$ Rozmowa z Mariuszem Borsiakiem...
} 
Władysława Bogdanowskiego. Jak sami twierdzą, podczas reporterskich peregrynacji mieli okazje słuchać tego typu relacji i postanowili przenieść formułę na olsztyński grunt. Postanowiono, że nie będą to tylko reporterskie relacje, a domknięta przestrzeń antenowa skoncentrowana wyłącznie na problematyce rajdowej. Debiut miał miejsce przy okazji samochodowych Rajdowych Samochodowych Mistrzostw Polski - Rajdu Kormoran. Wówczas uruchomiono pionierskie w skali kraju przedsięwzięcie antenowe. Na osobnej częstotliwości 105,7 MHz nadawano całodobowy program motoryzacyjno-muzyczny, a w nim relacje „na żywo", rozmowy z przedstawicielami branży motoryzacyjnej, policjantami. Program cieszył się dużą popularnością, przy zasięgu $60 \mathrm{~km}$, taką moc miał bowiem przyznany nadajnik, dzienną słuchalność obliczono na 50-60 tys. odbiorców ${ }^{16}$. W pierwszym roku był to pewnego rodzaju eksperyment, mimo techniczno-organizacyjnych kłopotów, niezwykle udany. Dziennikarze obsługujący wydarzenie musieli wykazać się niezwykłą dynamiką i konsekwencją, twierdzi Borsiak:

Dla nas to było przedsięwzięcie organizacyjne szalone, dlatego że wyzwanie techniczne po pierwsze. Trudny teren, lasy, nie wiadomo było, czy będzie zasięg, czy nie. Raz był, raz nie. To się wszystko rwało. Ale z czasem zaczęliśmy nabierać doświadczenia. I my się wówczas dzieliliśmy tymi odcinkami, każdy miał obsługiwać jeden. To było też szalone, zdawaliśmy relację z jednego odcinka, szybko wsiadaliśmy w samochód i jechaliśmy na kolejny. To się odbywało bardzo szybko. Adrenalina. Ale nie łamaliśmy przepisów. Wszędzie byli policjanci, o czym musieliśmy pamiętać. Przekazywaliśmy te relacje na gorąco, czas poszczególnych zawodników, czy coś się stało, czy potrzebna będzie naprawa. Dla nas to też było bardzo ciekawe doświadczenie, ponieważ gdy podjeżdża taka maszyna rozgrzana, trzeba otworzyć drzwi, zapytać tego zawodnika o jego wrażenia. Zawodnicy w takiej gorączce, która biła od samochodu, zapach tej rajdowej benzynki. Także to wszystko miało swój urok, fantastyczny kolor i smak, tę pracę bardzo lubiłem, pomimo tego spięcia ${ }^{17}$.

Pierwszym zadaniem Radia Rajdowego było precyzyjne rejestrowanie czasów i przekazywanie ich za pośrednictwem anteny. Zatem automatycznie Radio Rajdowe włączono do organizacji wewnętrznej rajdu. Dziennikarze byli na tyle wiarygodni, że dane pozyskiwane były przez jurorów i zawodników. Z informacji przekazywanych na antenie korzystały także rajdowe serwisy, które na podstawie danych $\mathrm{z}$ radia przygotowywały się do napraw samochodów ${ }^{18}$.

Rok później, w konsekwencji zmian technologicznych, miała miejsce pierwsza częściowa transmisja Rajdu Kormoran w Internecie, na istniejącej już od

${ }^{16}$ Zob. Archiwum Radia Olsztyn SA, Sprawozdanie Zarządu z Działalności Spółki Polskie Radio Rozgłośnia Regionalna w Olsztynie „Radio Olsztyn” S.A. w roku 1997, s. 21.

${ }^{17}$ Rozmowa z Mariuszem Borsiakiem...

${ }^{18}$ Ł. Lach, Jedyne takie radio, „WRC. Magazyn rajdowy” 2009, nr 8, s. 62-63. 
dwóch lat stronie Radia Olsztyn - ro.com.pl ${ }^{19} .1$ stycznia 1999 roku Radio Olsztyn przejęło częstotliwość 99,6 MHz obsługiwaną początkowo przez nadajnik w Giżycku, a od 1 kwietnia 2000 roku nadajnik w Miłkach. Wiązało się to z powstaniem województwa warmińsko-mazurskiego w nowym podziale administracyjnym Polski, a tym samym ze znacznym powiększeniem obszaru oddziaływania Radia Olsztyn. W tymże roku program Radia Rajdowego cieszył się bardzo dużą popularnością - przy zasięgu $60 \mathrm{~km}$, dzienną słuchalność oceniono na 50 tys. do 60 tys. słuchaczy ${ }^{20}$.

W 2000 roku w olsztyńskiej rozgłośni regionalnej uruchomiono serwer „na sztywno" podłączony do sieci. Program „na żywo" nadawany był w sieci, w formacie real audio, w maju transmitowany był w Internecie Rajd Kormoran. Na stronach WWW, po raz pierwszy, stworzono dokumentację fotograficzną i dźwiękową pod adresem - www.ro.com.pl/rajd/21.

Formalną siedzibą Rajdu Kormoran był Olsztyn, wobec tego studio-matka osadzone w siedzibie rozgłośni wydawało się jak najbardziej najbardziej zasadne; Jermakow twierdzi:

Rajd Kormoran był rozgrywany w Olsztynie. Ja dołączyłem do tego zespołu w 2000 roku. Podczas pierwszych lat nadawania było mnóstwo kłopotów technicznych. Zwłaszcza podczas kultowych oesów: Wymój - Mańki, Kortowo - Dorotowo, Stawiguda, Olsztyn - Dajtki. To był pamiętny rajd, kiedy Janusz Kulig wygrał z Krzysztofem Hołowczycem. Przełom 2000 roku. To była złota era polskich rajdów. To były duże budżety rajdowe, włączały się duże koncerny. Duże pieniądze, o których teraz kierowcy rajdowi mogą pomarzyć. Absolutna hossa. Kulig, Kuzaj, Hołowczyc, wielka trójka polskich rajdów „cięła” się niemiłosiernie. I my rok po roku to relacjonowaliśmy. To radio w różne strony zaczęło iść. To znaczy czasem było bardziej zabawowe, czasem bardziej poważne. My możemy sobie żartować i wesołe piosenki puszczać. Ale pamiętam takie sytuacje, gdy dochodziło do wypadków. Ofiar na szczęście nie było, ale byli ranni i trzeba było trochę profil mówienia, grania zmienić. Ale tak trwaliśmy. Doszliśmy do roku 2006. To było nadal radio nadawane z Olsztyna, gdzie gospodarze radia siedzieli w studio. Wówczas to byłem ja i Michał Porycki. Najdłuższa przerwa „niebycia” na antenie to było jakieś 10 minut. I w czasie tych 10-ciu minut trzeba było wszystko załatwiać, jeśli chodzi o jedzenie, inne potrzeby. A trzeciego dnia udało nam się taką sztuczkę zrobić, kiedy nie było oesów. Puszczaliśmy 15 minut muzyki i udawało się nam zdrzemnąć, choć na 10 minut ${ }^{22}$.

${ }^{19}$ Zob. Archiwum Radia Olsztyn SA, Sprawozdanie Zarządu z Działalności Spółki Polskie Radio Rozgłośnia Regionalna w Olsztynie „Radio Olsztyn” S.A. w roku 1998, s. 30.

${ }^{20}$ Zob. Archiwum Radia Olsztyn SA, Sprawozdanie Zarządu z Działalności Spółki Polskie Radio Rozgłośnia Regionalna w Olsztynie „Radio Olsztyn” S.A. w roku 1999, s. 31.

${ }^{21}$ Tamże.

${ }^{22}$ Rozmowa z Wojciechem Jermakowem... 
Zatem było to działanie szalenie intensywne, obliczone na całościowe zaangażowanie grona merytoryczno-technicznego.

W 2005 roku Rajd Kormoran zniknął z programu Mistrzostw Polski. I jest to data graniczna. Oczywiście pozostaje wciąż w zasięgu zainteresowań dziennikarzy sportowych, ale przestał być przedmiotem narracji Radia Rajdowego. Tak się jednak złożyło i nie ma w tym przypadku, że od tego roku 66. Rajd Polski stał się prestiżową rundą mistrzostw świata i został przeniesiony do podolsztyńskich Mikołajek. Niejako naturalnie stał się punktem odniesienia. Radio Rajdowe nadało wówczas 84-godzinną audycję motoryzacyjną ${ }^{23}$. W latach 2005-2008 stacja nadawała na jednej z częstotliwości posiadanych przez Radio Olsztyn: 102,2 bądź 99,6. W 2009 roku Krajowa Rada Radiofonii i Telewizji ponownie przyznała dodatkową częstotliwość rozgłośni - 93,5. Radio działało także na podstawie koncesji przyznanej przez Urząd Komunikacji Elektronicznej ${ }^{24}$. Można go było także tradycyjnie już słuchać w Internecie na łączach akademickiej sieci Olman. Popularność sieci szybko przerosła oczekiwania nadawcy i limit 500 połączeń trzeba było zwiększyć do ponad 5 tys. Tym samym Radio Rajdowe znalazło się w pierwszej setce internetowych rozgłośni z całego świata ${ }^{25}$.

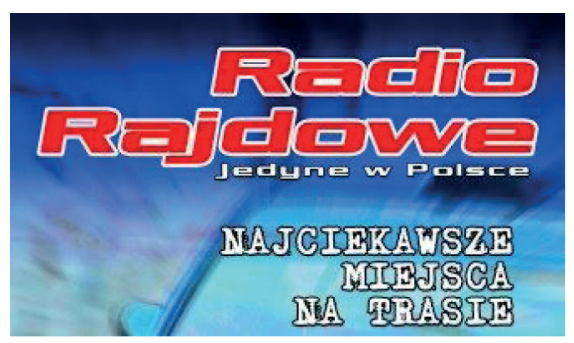

Fot. 2. Logo Radia Rajdowego

Źródło: http://ro.com.pl/72-rajd-polski-zobacz-i-posluchaj/01216452 [dostęp: 10.05.2016].

W 2012 roku, po raz ostatni, Radio Olsztyn wystąpiło o dodatkową częstotliwość dla Radia Rajdowego. Powodem takiej decyzji był nadajnik przydzielony rozgłośni, który posiadał zbyt małą moc, ograniczał teren nadawania, na co wskazuje dyrektor techniczny rozgłośni, Norbert Aksler:

Zrezygnowaliśmy z tego i piszemy do Krajowej Rady o pozwolenia na 72-godzinną zmianę programu na nadajniku w Miłakach. Żeby zasięg sięgał tam, gdzie odbywa się rajd. Tam jest wtedy inny program, rozszczepienie. Mamy przygotowane studio

${ }^{23}$ Zob. Archiwum Radia Olsztyn SA, Sprawozdanie Zarządu z Działalności Spółki Polskie Radio Rozgłośnia Regionalna w Olsztynie „Radio Olsztyn” S.A. w roku 2005, s. 30-31.

${ }^{24}$ Zob. Archiwum Radia Olsztyn SA, Sprawozdanie Zarządu z Działalności Spółki Polskie Radio Rozgłośnia Regionalna w Olsztynie „Radio Olsztyn” S.A. w roku 2009, s. 18.

${ }^{25}$ Ł. Lach, dz. cyt. 
w Olsztynie i reżyserkę. Natomiast drugie studio w wozie i z kodekiem ISDN-owym, tam gdzie siedzą w terenie redaktorzy prowadzący i trzy wozy, które jeżdżą po poszczególnych odcinkach specjalnych. Jeśli chodzi o wozy, to posługujemy się technologią IP, w wozie stacjonarnym, w bazie jest wóz z kodekiem ISDN, czyli stałym łączem ISDN. Całość tych urządzeń radiowych zbiega się w studiu i reżyserce w Olsztynie. I stąd jest nadawane do nadajnika w Miłkach. Technik jest obecny w bazie, a w Olsztynie jest realizator. Wykorzystujemy technikę dziś powszechnie dostępną i używaną w stacjach radiowych - IP; chodzi o dostęp do Internetu. Wszystkie samochody posługują się tą technologią. Pozwala to na zabezpieczenie dobrej jakości dźwięku we wszystkich miejscach nadawania. W wozie stacjonarnym korzystamy z łączy stałych ${ }^{26}$.

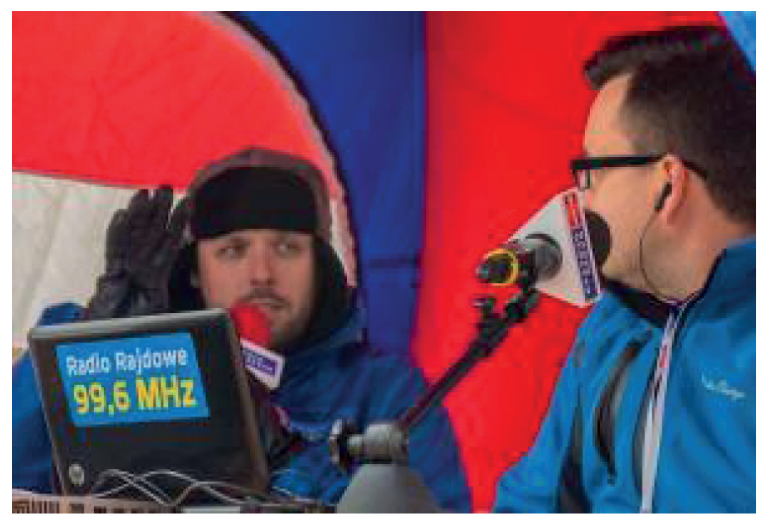

Fot. 3. Studio Radia Rajdowego w Mikołajkach Prezenterzy: Michał Porycki i Wojciech Jermakow

Źródło: http://ro.com.pl/72-rajd-polski-zobacz-i-posluchaj/01216452 [dostęp: 10.05.2016].

W 2012 roku studio-matka zostało na stałe przeniesione do Mikołajek, w pewnym sensie dopełniając formułę radia „na żywo”, które niejako stało się podstawową formułą rzetelnego i dosłownego obcowania z problematyką rajdową. Siedziba w sercu rajdu pozwoliła na przyjęcie zupełnie innej optyki i dosłowną penetrację miejsca; Jermakow zauważa:

To spełnienie marzenia i usytuowanie studia rajdowego w Mikołajkach w parku serwisowym. To wszystko jest nadal takie chałupnicze, ale [powstało] dzięki współpracy z gminą Mikołajki, która jest współorganizatorem rajdu. Dostajemy od nich scenę, oni nam to rozstawiają. Jest z nami radiowy wóz transmisyjny, są agregaty, jest oświetlenie. To są cztery dni od godziny 6:00 rano do 21:00-22:00. I od

${ }^{26}$ Rozmowa z Norbertem Akslerem, dyrektorem technicznym Radia Olsztyn przeprowadzona 18.05.2016 r.; zarejestrowana rozmowa w posiadaniu autorki tekstu. 
tego roku była przyczepa campingowa, zaplecze socjalne. Bez niej byśmy polegli. Wstawaliśmy o 5:00, przyjeżdżaliśmy do parku, kiedy to wszystko się budzi do życia, kiedy ci mechanicy „rajdówki” odpalają. A my w tym czasie, Michał odpalał radio, witał się ze słuchaczami, a ja szykowałem jajecznicę dla technika Norberta Akslera, Michała i dla siebie. Co roku mamy kłopot z pogodą. W 2012 roku było zimno, 2013 koszmarny Rajd Polski, który był rundą do mistrzostw świata. Robert Kubica przyjechał wtedy do nas po raz pierwszy. Tysiące kibiców, w ogóle niezliczone za jego sprawą. Drogi zamieniły się w grzęzawiska. Wykupiliśmy jedne z ostatnich gumowców. Wszystkie gumowce w sklepach w okolicznych miasteczkach zniknęły. To było obuwie obowiązujące. 2014 rok to powrót mistrzostw świata i 2015 rok ponownie. Rok 2014, na przemian było i zimno, i ciepło. Z kolei 2015 rok koszmarny upał. I tam padły słowa Macieja Świniarskiego: istne rajdowe i pogodowe inferno ${ }^{27}$.

W 2014 roku, w czerwcu, Radio Olsztyn po raz osiemnasty uruchomiło Radio Rajdowe. Od czwartku do niedzieli dzięki współpracy z Polskim Związkiem Motorowym miłośnicy rajdów samochodowych mogli na bieżąco śledzić najważniejsze wydarzenia z LOTOS 71. Rajdu Polski. Każdego dnia na częstotliwości 99,6 MHz reporterzy i dziennikarze przekazywali wyniki, wypowiedzi kierowców, rozmowy z organizatorami, kibicami i gośćmi rajdu. Prowadzący podpowiadali także, jak dotrzeć do punktów widokowych, jak uniknąć korków oraz jakich zasad przestrzegać, aby kibicowanie było bezpieczne; konsekwentnie realizowali koncepcję Radia Rajdowego ${ }^{28}$.

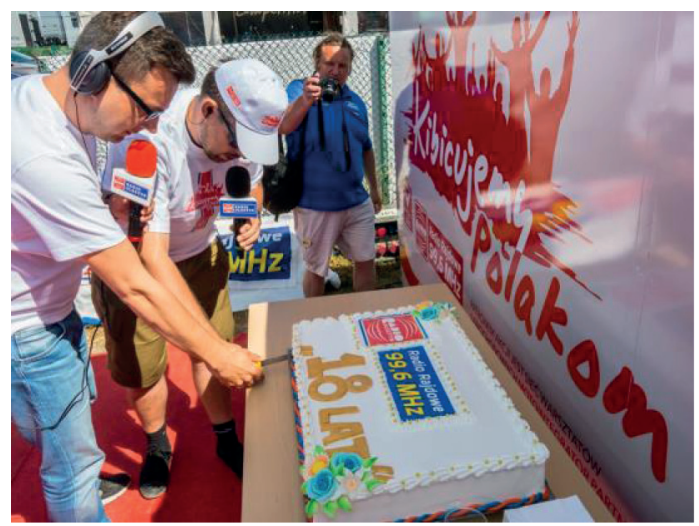

Fot. 4. Studio Radia Rajdowego w Mikołajkach

Prezenterzy: Michał Porycki i Wojciech Jermakow, reporter: Wojciech Chromy

Źródło: http://ro.com.pl/72-rajd-polski-zobacz-i-posluchaj/01216452 [dostęp: 10.05.2016].

${ }^{27}$ Rozmowa z Wojciechem Jermakowem...

${ }^{28}$ Zob. Archiwum Radia Olsztyn SA, Sprawozdanie Zarządu z Działalności Spółki Polskie Radio Rozgłośnia Regionalna w Olsztynie „Radio Olsztyn” S.A. w roku 2014, s. 26. 
Dopełniając historię Radia Rajdowego, należy wspomnieć, że w roku 2011 zaniechano nadawania pełnego programu monograficznego, były tylko przygotowywane cogodzinne relacje. Podobnie rzecz miała się w roku 2016.

\section{Wnioski}

Czym jest wobec tego Radio Rajdowe? Realizacją potrzeby innej stylistyki, odpowiedzią nadawcy publicznego na zapotrzebowanie społeczne, a może formą penetracji niszowej rajdowej problematyki? Jest to interaktywna, atrakcyjna formuła wybiegająca naprzeciw oczekiwaniom miłośników sportu motoryzacyjnego, ale także ciekawa figura zmieniająca postrzeganie radia jako jednokanałowego medium. Wszak jest to medium, które podąża za czasem, a jednocześnie nie traci swojej tożsamości. Wciąż jest intymną formą komunikowania nadawcy z odbiorcą, przy czym granica pomiędzy wskazanymi podmiotami momentami zupełnie się zaciera. Spójny, jednolity wizerunek wpisał Radio Rajdowe na stałe do kalendarium wydarzeń. Samo w sobie jest także eventem i interesującym projektem zaadaptowanym sprawnie do Internetu. Jest to kwintesencja korelacji nadawca-odbiorca, symbiotyczna struktura radiowa, łącząca w sobie stację matkę i kreatywnego ,potomka”. Jest to ciekawe zjawisko komunikacyjne, a z uwagi na rozwój technologiczny faktyczna sfera jego oddziaływania jest nieograniczona. Mam tu na myśli obecność równoległą w przestrzeni linearnej, w eterze, lecz także w przestrzeni WWW. Radio Rajdowe jest atrakcyjną propozycją w wielkim kiermaszu ofert radiowych.

Na zakończenie warto wspomnieć jeszcze o ciekawej implikacji Radia Rajdowego. Stało się ono inspiracją do przeniesienia świata realnego w przestrzeń fikcji literackiej. Jermakow, obecnie najistotniejsza antenowo postać w Radiu Rajdowym, napisał kolażowy teatr radiowy, słuchowisko zatytułowane Sponsor. Jest to oryginalne, powstałe na potrzeby radia i pod jego wpływem dzieło, wykreowane dzięki niezwykle głośnej i dynamicznej, w sensie dosłownym, inspiracji. Jak na słuchowisko przystało, jest napisane mową i myśli mową, nacechowaną przestrzenią realistyczną, $\mathrm{w}$ tym przypadku realizowaną $\mathrm{w}$ formule partycypacji, efekty specjalne bowiem pozyskiwane były u źródła, podczas rajdu. Reżyserami spektaklu są Marek Markiewicz i Jaromir Wroniszewski. W główne role wcielili się profesjonalni aktorzy i rajdowcy, m.in. Krzysztof Hołowczyc i Maciej Wisławski. Premiera słuchowiska miała miejsce na torze kartingowym w Olsztynie, gdzie zaproszeni byli rajdowcy z całej Polski, i na radiowej antenie. Jest ono umieszczone na stronie Radia Olsztyn w formie podcastu. Można zatem na różnych poziomach, w różnej stylistyce, w dowolnym czasie kontemplować przestrzeń rajdową. 


\section{Bibliografia}

Archiwum Radia Olsztyn SA, Sprawozdanie Zarządu z Działalności Spółki Polskie Radio Rozgłośnia Regionalna w Olsztynie „Radio Olsztyn” S.A. w roku 1997.

Archiwum Radia Olsztyn SA, Sprawozdanie Zarządu z Działalności Spółki Polskie Radio Rozgłośnia Regionalna w Olsztynie „Radio Olsztyn” S.A. w roku 1998.

Archiwum Radia Olsztyn SA, Sprawozdanie Zarządu z Działalności Spółki Polskie Radio Rozgłośnia Regionalna w Olsztynie „Radio Olsztyn” S.A. w roku 1999.

Archiwum Radia Olsztyn SA, Sprawozdanie Zarządu z Działalności Spółki Polskie Radio Rozgłośnia Regionalna w Olsztynie „Radio Olsztyn” S.A. w roku 2000.

Archiwum Radia Olsztyn SA, Sprawozdanie Zarządu z Działalności Spółki Polskie Radio Rozgłośnia Regionalna w Olsztynie „Radio Olsztyn” S.A. w roku 2005.

Archiwum Radia Olsztyn SA, Sprawozdanie Zarządu z Działalności Spółki Polskie Radio Rozgłośnia Regionalna w Olsztynie „Radio Olsztyn” S.A. w roku 2009.

Archiwum Radia Olsztyn SA, Sprawozdanie Zarządu z Działalności Spółki Polskie Radio Rozgłośnia Regionalna w Olsztynie „Radio Olsztyn” S.A. w roku 2014.

Connerton P., Jak społeczeństwa pamiętają, przekł. i wstęp M. Napiórkowski, Wydawnictwo Uniwersytetu Warszawskiego, Warszawa 1989.

Doliwa U., Radio społeczne: trzeci obok publicznego i komercyjnego sektor radiowy, Wydawnictwo Uniwersytetu Warmińsko-Mazurskiego, Olsztyn 2016.

Jermakow W., Łaczymy się z walcem. Jedyne takie Radio Rajdowe, „Co słychać” 2006, nr 5 (23), s. $2-3$.

Jędrzejewski S., Radio w komunikacji społecznej. Rola i tendencje rozwojowe, Wydawca Profi-Press Sp. z o.o., Warszawa 2003.

Kropacz-Szydłowska M., Od Ekspozytury Polskiego Radia do Radia Olsztyn S.A. Z dziejów olsztyńskiej radiofonii w latach 1992-1993, Polskie Towarzystwo Historyczne. Oddział: Instytut Dziennikarstwa i Komunikacji Społecznej UWM, Olsztyn 2012.

Lach Ł., Jedyne takie radio, ,WRC. Magazyn rajdowy” 2009, nr 8, s. 62-63.

Rozmowa z Mariuszem Borsiakiem, dziennikarzem Radia Rajdowego, przeprowadzona 15.06.2016 r.; zarejestrowana rozmowa w posiadaniu autorki tekstu.

Rozmowa z Norbertem Akslerem dyrektorem technicznym Radia Olsztyn, przeprowadzona 18.05.2016 r.; zarejestrowana rozmowa w posiadaniu autorki tekstu.

Rozmowa z Wojciechem Jermakowem, dziennikarzem Radia Rajdowego, przeprowadzona 15.05.2016 r.; zarejestrowana rozmowa w posiadaniu autorki tekstu.

\section{Netografia}

Odcinek Specjalny, http: //odcinekspecjalny.p1/ [dostęp: 10.05.2016].

Race Time Radio, RTR, http://tunein.com/radio/William-Hill-Racing-Radio-s149648/ [dostęp: 10.05.2016].

World Rally Championship, WRC, http://www.wrc.com/en/wrc/about-wrc/what-is-wrc/page/673672. [dostęp: 10.05.2016].

http://ro.com.pl/72-rajd-polski-zobacz-i-posluchaj/01216452 [dostęp: 10.05.2016]. 
Magdalena Szydłowska

The "Radio Rajdowe" Platform on Regional Polish Radio in Olsztyn

1998-2016

\section{(Summary)}

Radio, seen as an accompanying medium needs to participate in the evolution of needs: change its style, create new forms of mutual relations, make use of a multitude of genres resulting from its multimedia status. In a certain sense radio is becoming a new medium, although it happily avails itself of its previously acquired attributes. In this context, the subject we are addressing is clearly included in this definitional composition. "Radio Rajdowe" is a specific media construction, the only initiative of its kind in public radio in Europe. It is a form created by the presence of the broadcaster in the public space. A broadcaster that is its chronicler and participant. It is also an event and an interesting project, well adapted to the Internet. It is the quintessence of the broadcaster-listener correlation, a symbiotic radio structure, combining in one the parent station and its creative "progeny". It is an interesting communicative phenomenon, and thus worthy of such attention and analysis.

Keywords: radio, Radio Rajdowe, history, formatting. 